\title{
The Contents and Construction Method of Digital Economy as a New Driving Force
}

\author{
Tianjiao Luo* 1 \\ ${ }^{1}$ Renmin University of China \\ *Corresponding author. Email: 1026371557@qq.com

\begin{abstract}
The global economy has been strongly impacted by COVID-19, and the traditional economy has suffered a major setback. In the post epidemic era, how to break through the bottleneck of economic development and realize highquality economic development has become a difficult problem. This paper puts forward the idea of digital economy as a new driving force, sheds light on its resilience in the post epidemic era, analyzes the existing problems in its development in China, and puts forward its methods of construction as a new driving force in the post epidemic era, so as to further promote its standardized, intelligent and industrialized development in China.
\end{abstract}

Keywords: digital economy, high-quality development, economic transformation, post epidemic era, new driving force

\section{INTRODUCTION}

COVID-19 has strongly impacted the world economy as well as Chinese economy. In the short run, the pandemic will inevitably lead to a decline in personnel mobility, which will do great harm to transportation, catering, retail, tourism, warehousing, real estate, construction and other industries. In the long run, consumer confidence will remain insufficient and international tourism, investment and other industries will continue to suffer from the pandemic. Digital economy, as an optimized driving force, is urgently needed to lessen the negative impact of the epidemic, promote high-quality economic development comprehensively and start a new stage of modernization when Chinese economy is in a critical period of structural adjustment and transformation [1].

CCID think tank believes that the pandemic impacting the global economy can also become a catalyst for the development of digital economy, which can serve as a choice to effectively hedge against the negative effects of the pandemic. In the post epidemic era, digitalized industries can maintain and even expand the macro economy. Digitalized, networked and intelligent development of manufacturing industry can further improve the efficiency of public sector and boost economic recovery and growth.

\section{DIGITAL ECONOMY IS A NEW DRIVING FORCE}

Digital economy is a new economy after agricultural and industrial economy in human history. Different from the dependence of agricultural economy on land and industrial economy on capital, in the era of digital economy, data has successfully surpassed land, capital, labor to become an extremely important factor of production, and has become a new promising driving force for economic development [2].

Since the reform and opening up, China has established a socialist economic system full of vitality by fully mobilizing labor, land, technology, capital and other production factors, and created a great economic miracle. However, with the decrease of demographic dividend and resources, the substantial increase of economic volume and the change of the world economic environment, the initial economic driving force began to decline. China's economy will face huge pressure of transformation in realizing a well-off society in an all-round way. Finding a new driving force to sustain healthy growth of Chinese economy in the future is a challenge for the government and country to build a well-off society in an all-round way and a modernized socialist country.

At present, the construction of socialist modernization in China has faced the aggravating anti-globalization trend and the global economic recession caused by 
COVID-19. To cater to the needs in current economy, on the construction of a better market-oriented system and mechanism of allocating production factors was released by the CPC Central Committee and the State Council in April 9, 2020. In this document, data is listed as one of the five production factors, the other four being land, labor, capital and technology, which is a clear signal that data has become one of the five officially-recognized production factors in driving economic growth. The accelerating digital economy is becoming a reality.

As a new driving force to deal with insufficient economic development power in the post epidemic era and promote industrial transformation, digital economy has been widely recognized and paid more attention [3].

\subsection{Data assets as a production factor}

With the development of science and technology, great changes have taken place in processing information and data in different countries. In this process, data has changed from the original information carrier to a factor of production in the information age. As a new production factor, value-oriented data applications are constantly developed in the era of big data, which promotes the development of digital economy in various fields. New technologies are developing, new models are emerging, new businesses and trade are appearing, new markets are expanding, and new fields are further developing, which is of great significance to the national economy, finance and taxation, traditional industries, employment and consumption and so on. New products, new fields and new markets are developed on the basis of data elements such as online transaction, online payment, online consumption, artificial intelligence, digital media and digital industry, and they will become the supporting force of the new economy [3]. From 2015 to 2019, the new driving force index of China's economic development is 124.8, 159.1, 204.1, 269.0 and 332.0 respectively, with an increase of $24.8 \%, 27.5 \%, 28.3 \%$, $31.8 \%$ and $23.4 \%$ over the previous year, which is much faster than the economic growth rate of the same period and is a bright spot of China's economic development in recent years.

\subsection{Data assets as production and organization method}

Data assets, as a factor of production, can not only create value, but also promote the transformation and innovation of traditional industries and generate greater value by driving the transformation of traditional industries and changing the mode of production organization. Digital economy can help transform and innovate production mode in the three traditional industries. In the primary industry, intelligent agriculture, forestry, animal husbandry and fishery based on data information are constantly growing. This new agricultural production mode has changed the traditional backward farming mode, greatly reduced the cost and improved the production efficiency. Information agriculture is an important means to deal with the relative lack of resources and low efficiency in China. In the secondary industry, the new digitalized industry based on data is gradually developing and can greatly improve the production and management efficiency when combined with new technologies such as artificial intelligence. In the tertiary industry, big data and cloud computing based on data assets can greatly improve the matching efficiency and service convenience. The satisfaction of consumption demand and the upgrading of services break through the original constraints. Production is more adaptable to the consumption demand, and the boosting effect of consumption to production is more direct. By reconstructing the "production function" of traditional industries, data assets can stimulate the new driving force of traditional industries.

\subsection{Data assets as the driving force of new technology development and institutional reform}

As an important factor of production, data elements can become data assets and bring digital economy, which will fundamentally innovate and improve the economic and social system in various aspects, and improve the efficiency of the whole society. It is bound to stimulate and push forward the new economy comprehensively. Under the new normal of China's economy, the extensive economic growth mode of high input, high consumption, high emission and low efficiency has been unsustainable and the transformation from extensive to intensive development is irreversible. In the era of declining population and resource dividends, the intensive development mode of high technology, low consumption, high output and high quality requires all fields and industries to greatly improve resource utilization, talent contribution and service satisfaction. The allocation of limited resources should be optimized to create greater value and meet greater demand. E-government, social management and other fields based on big data can greatly improve the efficiency and quality of administrative services and people's satisfaction, happiness and security. It can be seen that data assets, as the driving force of reform, has become a vital new driving force under the new normal and can help us achieve intensive economic growth.

\section{STRONG RESILIENCE OF DIGITAL ECONOMY}

In the face of the abrupt pandemic, digital economy has shown great development resilience, grown against the trend, and provided impetus to the recovery and growth of the world economy. This resilience is particularly evident in China. 5G, artificial intelligence, 
Internet of things and other new technologies have been widely used. E-commerce, video conference, online shopping, online education, sharing platform, collaborative office, telemedicine and other "non-contact economy" are developing fast. The added value of information transmission, software and information technology service industry has increased by $16.9 \%$, and the online retail sales of physical goods nationwide has increased by $14.8 \%$. It has become a "new force" to restore the production of enterprises and a "stabilizer" to hedge the downward pressure of economy [4].

Zhang Xinhong, chief officer of the National Information Center, said that the pandemic has spawned a number of new demands, such as online meetings, teaching and medical treatment, which in turn have accelerated digital technology innovation. Wang Jun, member of the academic committee of China International Economic Exchange Center and chief economist of Zhongyuan Bank, believes that with the accelerated construction of new infrastructure such as 5G network and data center, digital technologies such as artificial intelligence, blockchain, cloud computing, big data, edge computing and Internet of things will be more widely applied, and digital economy is expected to become a new momentum and new growth point of China's economy.

\subsection{Digital economy shows resilience against "anti-globalization"}

The Competitive Power Development Report on Digital Economy Worldwide 2020, released by the Academy of Social Sciences in Shanghai on January 5, 2021, pointed out that the virtuality of data and the noncontact nature of digital economy allowed it to overcome the adverse effects of the pandemic, accelerate the development and show resilience against the "antiglobalization" [5].

Economic globalization brings not only prosperity and development, but also conflict, unfair distribution and environmental pollution. After the global financial crisis in 2008, the economy did not recover as expected, but further fell into the downturn. The continuous downturn led to the escalation of trade protectionism, the weakening of global multilateral mechanisms, and the fragmentation of regional trade and investment agreements. Unilateralism, isolationism, decoupling of science and technology and other "anti-globalization" waves rise here and there, and trade protection, border wall building, immigration control and other ideological trends surge. Digital economy is a powerful weapon to fight against anti-globalization. With the innovation and application of information technology and artificial intelligence in various fields, informatization is developing in depth. Informatization reflects the development of information industry and its contribution to economic growth, and digitization will further break through the specific industrial boundary and bring about the transformation of the overall economic model. When the global trade and investment are cut off, and the global industrial chain and industrialization system are disrupted, cross-border e-commerce and digital economy can serve as a bridge to connect them.

\subsection{Digital economy shows resilience in fighting epidemic}

Digital technology and economy plays an important role in preventing and controlling global epidemic and recovering economy and has become the stabilizer of social operation. In the future, international cooperation in the field of digital economy will be unstoppable [4]. In 2020, the pandemic hit the world and some developed countries have implemented a comprehensive "sealing up", which has caused a huge impact on the global industrial supply chain and a sharp decline in global production and international trade. The United States, Japan and other countries have put forward the idea of replacing globalization with domestic production and regionalization. Globalization has even become the "scapegoat" of the pandemic, which gives rise to the upsurge of "anti-globalization". In such a situation, the global digital economy is witnessing a stable development, which shows that "sealing up" and "blocking" can not stop consumers from enjoying digital services and stop the innovation and development of the digital economy worldwide. The rapid development of digital technology enables people to know the spread of the epidemic in the shortest time. Big data can analyze the flow of people to implement necessary isolation measures and reduce the probability of transmission. In addition, the "stay-at-home economy" has accelerated the development of online education and office and quickened the economic transformation. The rapid development of digital economy has also accelerated the development of public services such as intelligent transportation, medical care, and education. It is changing people's lifestyle and enterprises' office mode, hedging the negative impact of the epidemic effectively and showing resilience in fighting against the epidemic.

\subsection{Digital economy has become a long-term factor to fight against "anti-globalization"}

The outstanding performance of digital economy in epidemic prevention and control and its key role in stabilizing production and life highlight its hedging power against the tide of "anti-globalization" and its power of turning crisis into opportunity by innovation. It is accelerating the change of our production and life style and also revolutionizing the cooperation mode of international trade and transnational investment. The economic roots of multilateralism, international cooperation, free trade and global allocation can be seen from the perspective of the change of production mode. 
Digital services, trade, finance and governance have greatly maintained the stability of the global industrial supply chain and promoted closer connection of all countries in terms of enriching business forms, improving trade welfare, optimizing capital allocation and promoting transnational cooperation. The new cooperation opportunities brought by digital economy will help to create Economic Globalization V 2.0, deal with the "anti-globalization" crisis effectively, and have a lasting and far-reaching impact on economic and social development of all countries, economic and trade pattern, international order, global governance system, and even the advance of human civilization.

\section{PROBLEM IN DEVELOPING DIGITAL ECONOMY IN CHINA}

\subsection{Weak foundation in digitalizing industry}

The rapid development of digital economy is shown more obviously in consumption in China, but not in production. Well-developed and applicable digital technologies can only support consumption at present, but can not provide technical support for industrial digitization. Industrial network standards and technologies are basically controlled by foreign companies, while high-end industrial sensors, industrial control systems and key industrial software are basically monopolized by foreign countries. The global industrial field bus and industrial Ethernet standard protocols are all controlled by a few foreign enterprises, and more than 95\% of the industrial Ethernet network equipment market is monopolized by foreign countries. In the field of industrial control, more than $95 \%$ of the high-end PLC market and more than $50 \%$ of the high-end DCS market are monopolized by foreign manufacturers. High-end industrial software such as CAD, CAE, PLM designed by foreign enterprises occupy $90 \%$ of the market in domestic aerospace, aviation, automotive and other industries .

\subsection{Insufficient legal policies and systems}

Different from the traditional agricultural and industrial economy, digital economy is a new economic form. Data has become a key production factor or resource to drive economic operation, and big data has become a valuable data asset. This will lead to fundamental changes in property right system, incentive mechanism, credit relationship, market organization and rules in digital economy market. Because its basic theoretical research lags far behind the needs of guiding economic development, and the corresponding laws, regulations, and policies are too lagging to encourage innovation, China's digital economy just follows suit, and with too much emphasis on the growth of quantity instead of on quality, it is difficult to innovate independently.

\subsection{Insufficient ability in integrating data resources and potential risks in digital security}

At present, the data resources of all industries are isolated in different systems and the administrative departments are also relatively isolated in data sharing, which leads to inadequacy in data integration and activation and makes data sharing difficult. Network threats, such as public Internet viruses, Trojans, and advanced persistent attacks, threaten the safety of key industries in national economy, including manufacturing, finance, transportation, and energy. Major network security incidents may happen when they are attacked by the network threats, and economic and social security and even national security will be seriously threatened. The production equipment will develop from mechanization to digitization, networked and intelligence, and it will bring new security risks when they are connected to the industrial Internet. These devices are not only the targets of network attacks, they themselves will become the source of attacks once controlled, and the destructive power will be magnified exponentially.

\subsection{Obvious weakness in digital transformation for enterprises}

Digital transformation is not a simple application of information technology. It involves the integration of knowledge model, mechanism model and data model used in the enterprise to rebuild and reshape its business and to change the past production mode and the generation mode of value chain. At present, the digital transformation of enterprises in China is still characterized by low short-term benefits and high costs and risks. Therefore, enterprises generally don't want to, and even don't dare to make such a transformation. When they decide to carry out digital transformation, they do not know how to do it since they are not good at it. At the same time, many enterprises will be confronted with many barriers in the process of industrial digitization.

\subsection{Many challenges facing digital economy}

At present, insufficient fund from the government and enterprises has greatly influenced digital transformation in China's traditional industries. The lack of digital talents is restricting China's economic digitization. The widening digital gap, the invasion of privacy, and the security risks in information technology, the winner taking it all, and the reshuffling of international trade rules pose great challenges to its development.

\section{STIMULATE DIGITAL ECONOMY AS A NEW DRIVING FORCE}

Taking Internet technology as the core and data as the key element, digital economy has the characteristics of rapid product iteration, better user participation, increased 
marginal benefits, and more consumer demand. It is an important driving force in optimizing and upgrading industrial structure, generating new business forms, and stabilizing economic development in the post epidemic era.

\subsection{Theoretical research of digital economy needs to be strengthened}

The rapid development of digital economy poses great challenges to the existing economic theory. Traditional economic theory pursues sufficient information, but data sharing involves privacy protection. Information has had a huge impact on consumption, but it is hard to define and calculate its impact statistically in theory. A unification in its contents, classification, definition, standard and other aspects must be achieved to strengthen the theoretical research of digital economy. In many fields such as macro-economy, industrial economy, enterprise development, market theory and consumption theory, a deeper understanding of the impact of existing theories on the development, regulations and standards of digital economy is needed to provide theoretical support for developing digital economy.

\subsection{Consolidate the foundation of industry digitization and win the leadership in formulating new standards of digital economy}

Digital infrastructure construction needs to be accelerated to provide an important guarantee for its development. In accordance with the central government's decision, by taking applications as the guidance, resource integration and joint construction and sharing need to be strengthened, and by taking $5 \mathrm{G}$ network, data center and other digital infrastructure construction as a pulling force, the services and efficiency of traditional infrastructure need to be optimized and improved to lay a solid hardware foundation for the rapid development of digital economy . When the standards and specifications of products and services of digital economy are formulated in time, the data resources can be fully shared and the development work of subdivision fields will not be repeated and wasted. At the same time, efforts need to be made to grasp the international right of speech and leading power in formulating digital economy standards. General secretary Xi Jinping pointed out that we should adopt asymmetric development strategy and make better use of our advantages. In the global digital competition, China should pursue asymmetric development. For example, the potential of $5 \mathrm{G}$ and related fields should be fully tapped. After the rules are formulated, on the one hand, efforts have to be made in developing the key core technologies, on the other hand, attention should be paid to the development of the whole industry chain, industrial robots, high-end industrial software, and its quick application.

\subsection{Promote data fusion and eliminate security risks}

The exchange of data and information is the basis of digital economy. The government should make great efforts to connect the isolated data and information fields and industries and establish a supervised information sharing platform, so as to maximize data and information sharing and create the greatest value. Data collection, storage, transaction, flow and other links need to be managed and supervised, because data security will affect many fields and industries, and information leakage and user data trafficking can pose wide-ranging risks. Only by adhering to data security laws, can national security, business interests of enterprises and personal privacy be better protected.

\subsection{Strengthen the training of digital talents and improve the digital literacy of the whole population comprehensively}

In the post epidemic era, the global digital economy has entered a new stage of fast innovation and deep integration. It has expanded from the demand side to the supply side, and the focus has shifted from the consumption to the production. The "demographic dividend", based on a large number of Internet users and aimed to promote the digital transformation in consumption, is different from the "talent dividend" based on the training of digital talents and the improvement of digital literacy of the whole people. Efforts should be made to train more digital talents and expand digital training in Internet, Internet of things, big data, cloud computing and artificial intelligence. Digital skill training should be provided to new growing labor force and unemployed people. The scale of digital skill training should be expanded in big data analysis, software programming, industrial software and data security. National professional qualification directory should be established and qualification accreditation should be implemented. Talent training mode has to be innovated, the network operation ability of education and training institutions needs to be improved and all-process networked training mode needs to be developed.

\section{CONCLUSION}

It can be predicted that in the post epidemic era, digital economy will develop rapidly in China. By taking the Internet of things as the underlying technology and by developing artificial intelligence, it, as a new driving force of economic development, will continue to infiltrate and empower all fields and industries, drive the transformation and upgrading of traditional industries, and promote the high-quality development of economy. 
Data creates value and innovation drives the future. At the start of the new journey of high-quality development in the 14th Five Year Plan and the new journey of socialist modernization, we should speed up the construction of digital economy, smart society and network power and solidly promote the standardized, industrialized and intelligent development of digital economy, so as to achieve stability and further progress.

\section{REFERENCES}

[1] Liu Gongrun, Feb 28, 2020, digital economy is the "best option" in promoting the economic development in the post epidemic period, www.yicai.com.

[2] UNESCO International Center for creativity and sustainable development, Feb 25, 2021, digital economy presents strong development resilience and becomes a new driving force for global economic growth.

[3] Liu Ruiming, July 8, 2020, three levels of digital economy boosting new momentum, The Paper.cn.

[4] Ma Xiangdong, Feb 18, 2021, digital economy shows strong resilience in resisting "antiglobalization" [n], Guangming Daily.

[5] Wang Zhen etc., Dec 1, 2020, The Competitive Power Development Report on Digital Economy Worldwide (2020) [R] 